CLINICAL STUDY

\title{
Tumour recurrence and enlargement in patients with craniopharyngioma with and without GH replacement therapy during more than 10 years of follow-up
}

\author{
D S Olsson, M Buchfelder ${ }^{1}, \mathrm{~K}$ Wiendieck ${ }^{1}, \mathrm{~N}_{\text {Kremenevskaja }}{ }^{1}$, B-Å Bengtsson, K-E Jakobsson ${ }^{2}$, M Jarfelt $^{3}$, \\ G Johannsson and A G Nilsson \\ Department of Endocrinology, Sahlgrenska University Hospital, Gröna Stråket 8, SE-413 45 Gothenburg, Sweden, ${ }^{1}$ Department of Neurosurgery, \\ University of Erlangen-Nuremberg, 91054 Erlangen, Germany, ${ }^{2}$ Department of Neurosurgery, Sahlgrenska University Hospital, SE-413 45 Gothenburg, \\ Sweden and ${ }^{3}$ Division of Pediatric Hematology and Oncology, The Queen Silvia Children's Hospital, SE-416 85 Gothenburg, Sweden \\ (Correspondence should be addressed to D S Olsson; Email: daniel.olsson@medic.gu.se)
}

\begin{abstract}
Objective: Most patients who have been treated for craniopharyngioma (CP) are GH deficient (GHD). GH replacement therapy (GHRT) may stimulate tumour regrowth; and one of the concerns with long-term GHRT is the risk of tumour progression. Therefore, the objective was to study tumour progression in CP patients on long-term GHRT.

Design: Case-control study.

Patients and methods: The criteria for inclusion of cases were: i) GHD caused by CP; ii) GHRT > 3 years; and iii) regular imaging. This resulted in 56 patients (mean age at diagnosis $25 \pm 16$ years) with a mean duration of GHRT of $13.6 \pm 5.0$ years. As controls, $70 \mathrm{CP}$ patients who had not received GHRT were sampled with regard to follow-up, gender, age at diagnosis and initial radiation therapy (RT). Results: The 10-year tumour progression-free survival rate (PFSR) for the entire population was $72 \%$. There was an association (hazard ratio, $P$ value) between PFSR and initial RT $(0.13,<0.001)$ and residual tumour $(3.2,<0.001)$. The 10 -year PFSR was $88 \%$ for the GHRT group and $57 \%$ for the control group. Substitution with GHRT resulted in the following associations to PFSR: GHRT (0.57, $0.17)$, initial RT $(0.16,<0.001)$, residual tumour $(2.6,<0.01)$ and gender $(0.57,0.10)$. Adjusted for these factors, the 10-year PFSR was $85 \%$ for the GHRT group and $65 \%$ for the control group. Conclusions: In patients with CP, the most important prognostic factors for the PFSR were initial RT and residual tumour after initial treatment. Long-term GHRT did not affect the PFSR in patients with CP.
\end{abstract}

European Journal of Endocrinology 166 1061-1068

\section{Introduction}

Craniopharyngiomas (CPs) are histologically benign suprasellar tumours with a strong tendency towards tumour progression and a capacity to invade the surrounding tissues (1). The primary tumour treatment for CP includes surgery and, in selected cases, radiation therapy (RT). In many cases, the tumour's volume effect and/or the tumour treatment result in panhypopituitarism $(2,3)$.

Studies on hypopituitary CP patients have shown an increased standard mortality rate (SMR) (2.9-9.3), which was significantly higher than that in other groups of patients with hypopituitarism $(4,5,6)$. The main causes of the increased SMR were cerebro- and cardiovascular accidents. Before the introduction of GH replacement therapy (GHRT), hypopituitarism in patients with a variety of causes including pituitary tumours was associated with a reduced quality of life $(7,8)$, a reduced bone mass (9) and an increased mortality, especially from vascular diseases $(4,5,10)$.
GHRT was introduced in the early 1990s. Studies have shown an improvement in quality of life, bone mass and a reduction in several vascular risk factors in patients with hypopituitarism receiving $\operatorname{GHRT}(11,12,13)$. It has been shown that $\mathrm{CP}$ patients with GH deficiency (GHD) benefit to the same extent from GHRT as nonfunctioning pituitary adenoma (NFPA) patients with GHD (14). The more severe hypopituitarism and the higher mortality rate in $\mathrm{CP}$ patients compared with NFPA patients emphasise the need for optimal replacement therapy in CP patients.

Because of the known mitogenic effects of $\mathrm{GH}$, it has been feared that GHRT may increase tumour recurrence or tumour enlargement in patients with a history of pituitary tumours $(15,16)$. Recent findings indicate that this is not the case in patients with NFPA $(17,18)$. It is well known that CPs have a high tumour progression rate - in fact after 10 years of follow-up around half of all CP patients who have not received RT develop tumour progression (1). The aim of this study 
was therefore to address the safety issue of whether long-term GHRT is associated with an increased frequency of recurrence or enlargement of CPs. A secondary aim was to obtain new long-term followup data on tumour progression in patients with $\mathrm{CP}$.

\section{Subjects and methods}

The study was performed as an open prospective longitudinal case-control study of consecutive CP patients with hypopituitarism and GHD in order to study the effects of long-term GHRT at the Department of Endocrinology, Centre for Endocrinology and Metabolism at the Sahlgrenska University Hospital, Gothenburg, Sweden. Controls were sampled among CP patients not treated with GHRT at the ErlangenNuremberg University Hospital, Germany.

\section{Patients treated with GHRT}

Patients treated with GHRT were selected based on three inclusion criteria: i) hypopituitarism and GHD caused by CP; ii) GHRT for at least 3 years; and iii) imaging performed before commencing GHRT and after at least 2 years of treatment. A total of 56 patients with $\mathrm{CP}$ were eligible for inclusion in the study. The primary treatment of the tumours performed between 1969 and 2005 (the vast majority in the 1980s and 1990s) is presented in Table 1. The surgical approach was transcranial in 47 cases $(89 \%)$ and transsphenoidal in six cases $(11 \%)$. The percentage of patients receiving RT, either as part of the primary treatment (30 patients) or as treatment due to tumour progression (five patients), was $63 \%$. When RT was a part of the primary treatment, the method used was conventional fractionated external radiotherapy except in two patients who were treated with stereotactic radiotherapy (Table 1).

The average observation period on GHRT was 13.6 \pm 5.0 years. At final imaging, 43 patients $(77 \%)$ were examined with magnetic resonance imaging (MRI) and 13 patients (23\%) with computed tomography (CT). GHD was diagnosed using established criteria (11). The GH dose was titrated individually in order to maintain serum insulin-like growth factor 1 (IGF1) levels within the agerelated reference range $(19,20)$. The average GH dose for the enrolled patients at the end of the observation period was $0.45 \pm 0.12 \mathrm{mg} /$ day (mean \pm s.D.) for men and $0.72 \pm 0.44 \mathrm{mg} /$ day for women. At the end of the observational period, all patients had reached adulthood. The percentage of patients who had zero, one, two or three additional deficiencies beside GHD was 2, 5, 7 and $86 \%$ respectively. Diabetes insipidus was present in 50 patients $(89 \%)$. All patients were monitored and treated for additional hormonal deficiencies besides GHD.

Informed written consent was obtained from all patients. The study was approved by the Regional Ethics Review Board at the Sahlgrenska Academy, University of Gothenburg, Sweden.

\section{Patients not treated with GHRT}

A group of $70 \mathrm{CP}$ patients not treated with GHRT was sampled from the hospital database at the ErlangenNuremberg University Hospital. The sampling process involved three mandatory criteria (diagnosis, type of initial treatment and status of GHRT) and four dispositive criteria (gender, age, age at diagnosis and duration of follow-up). The results of the sampling process are shown in Table 1.

The primary treatment of the $\mathrm{CP}$ tumours is presented in Table 1. The surgical approach was transcranial in 45 cases $(71 \%)$ and transsphenoidal in 18 cases $(29 \%)$. The percentage of patients for whom RT was part of the tumour treatment, either as part of the primary treatment (23 patients) or as treatment due to tumour progression (nine patients), was $46 \%$. When RT was a part of the primary treatment, the method used was conventional fractionated external radiotherapy (Table 1).

Table 1 Details of enrolled patients: gender distribution, age, age at diagnosis, observation period, primary treatment, and proportion of patients with a residual tumour after primary treatment.

\begin{tabular}{lll}
\hline & $\begin{array}{l}\text { CP treated with } \\
\text { GHRT }(n=56)\end{array}$ & $\begin{array}{l}\text { CP not treated with } \\
\text { GHRT }(n=70)\end{array}$ \\
\hline Gender (M/F; \%) $^{\text {Age }}$ (years) & $57 / 43$ & $49 / 51$ \\
Age at diagnosis $^{\text {a }}$ (years) & $46.6 \pm 16.1(22-75)$ & $45.7 \pm 16.2(6-76)$ \\
Observational period $^{\mathrm{a}}$ (years) & $25.1 \pm 16.4(4-62)$ & $32.3 \pm 16.9(2-65)$ \\
Primary treatment $n$ (\%) & $13.6 \pm 5.0(3-28)$ & $13.4 \pm 7.8(3-34)$ \\
Surgery alone & & \\
Surgery combined with RT & $25(45)$ & $45(64)$ \\
Cyst puncture alone & $28(50)$ & $18(26)$ \\
Cyst puncture combined with RT & $1(2)$ & $2(3)$ \\
RT alone & $2(4)$ & $4(6)$ \\
Residual tumour after primary treatment $n(\%)$ & $0(0)$ & $33(47)$ \\
\hline
\end{tabular}

$\mathrm{CP}$, craniopharyngioma; GHRT, GH replacement therapy; RT, radiation therapy.

a alues are presented as mean \pm s.D. (range). 
The average follow-up period from the primary treatment to the last imaging examination was $13.4 \pm 7.8$ years. At the final imaging, 52 patients $(74 \%)$ were examined with MRI and 18 patients $(26 \%)$ with CT. The percentage of patients who had zero, one, two or three other deficiencies than $\mathrm{GHD}$ was $13,17,34$ and $36 \%$ respectively. Diabetes insipidus was present in 33 patients $(47 \%)$.

Informed written consent was obtained from all patients.

\section{Methods: evaluation of tumour progression with and without GHRT}

Patients treated with GHRT were divided into two groups on the basis of their tumour status before commencement of GHRT. Patients with a known residual tumour were categorised at the end of the observational period as to the presence or absence of tumour enlargement. Patients without any visible residual tumour at baseline were categorised either as having a recurrence or no recurrence at the end of the observation period. Tumour status was evaluated by regular imaging of the sella turcica and its surroundings throughout the follow-up period. Tumour recurrence or enlargement was determined by comparison of the imaging at the end of the observation period compared with baseline, before commencement of GHRT. All tumour recurrence or enlargement, regardless of size or clinical relevance, resulted in categorisation as recurrence or enlargement at the time it was first detected on imaging. Tumour progression was defined as either tumour recurrence or tumour enlargement. Recurrence and enlargement were classified as being of clinical significance if any change in the clinical management was necessary. Change in clinical management was defined as intervention with cyst puncture, surgery or radiotherapy. All imaging was performed as part of a routine clinical surveillance programme, which was individualised based on age and tumour characteristics. Serum IGF1 concentration was determined by hydrochloric acid ethanol extraction RIA. IGF1 SDS were calculated as described previously (21).
Patients not treated with GHRT were evaluated in the same way as patients treated with GHRT, with the exception of the definition of the baseline, which was set to the time of the first tumour treatment.

\section{Statistical analysis}

All descriptive statistical analyses are presented as mean values and S.D. The mean of IGF1 values and SDS were compared between GHRT patients with and without a tumour progression by Student's $t$-test after ascertaining the assumption of normality. Kaplan-Meier survival curves were obtained to describe the progression-free survival (PFS) of patients in Table 2. The log-rank test was used to compare tumour progression times between subgroups. A proportional hazard model was used to analyse the impact of the potentially influential variables of gender (male $(=1)$ vs female $(=0)$ ), age at diagnosis, residual tumour after primary treatment, initial RT and GHRT. Hazard ratios (HRs), 95\% confidence intervals (CIs) and $P$ values are presented. A SAS macro (22) was used to calculate the adjusted survival probabilities including a 95\% CI, stratified by GHRT. The level of significance was set at $P<0.05$ (twosided test). Statistical analyses were performed using SPSS 18.0 (Chicago, IL, USA), SAS 9.2 (Cary, NC, USA) and Matlab 7.9.0 (Natick, MA, USA).

\section{Results}

\section{All patients: long-term follow-up}

Of $126 \mathrm{CP}$ patients, 39 (31\%) developed tumour progression during the follow-up period. The PFS rates (PFSRs) at 10 and 15 years were 72 and $67 \%$ respectively (Table 2). Tumour progression was observed after primary tumour treatment with surgery alone in 32 patients, surgery combined with RT in four patients, cyst puncture alone in one patient and combined cyst puncture and RT in two patients. The

Table 2 Tumour progression-free survival rates for the entire population and subgroups divided depending on treatment with GHRT, initial RT and residual tumour after primary treatment.

Progression-free survival at:

\begin{tabular}{|c|c|c|c|}
\hline & \\
\hline & 5 years $(\%)$ & 10 years $(\%)$ & 15 years $(\%)$ \\
\hline All CP patients $(n=126)$ & 82 & 72 & 67 \\
\hline No initial RT and no residual tumour $(n=56)$ & 78 & 66 & $57^{\mathrm{b}}$ \\
\hline No initial RT and residual tumour $(n=17)$ & 47 & 32 & 24 \\
\hline Initial RT and no residual tumour $(n=21)$ & 100 & 100 & 90 \\
\hline Initial RT and residual tumour $(n=32)$ & 91 & 82 & 72 \\
\hline CP patients treated with GHRT $(n=56)$ & 91 & 88 & 79 \\
\hline Adjusted for uneven distributed factors ${ }^{a}$ & 88 & 85 & 72 \\
\hline CP patients not treated with GHRT $(n=70)$ & 75 & 57 & 53 \\
\hline Adjusted for uneven distributed factors ${ }^{\mathrm{a}}$ & 79 & 65 & 60 \\
\hline
\end{tabular}

$\mathrm{CP}$, craniopharyngioma; GHRT, GH replacement therapy; $\mathrm{RT}$, radiation therapy.

${ }^{a}$ Adjusted with COX regression for initial treatment with RT, residual tumour after primary treatment and gender.

bLast event recorded at 13.1 years of follow-up. 
Table 3 Treatment targeting tumour progression in patients with and without GHRT depending on initial RT and the presence of residual tumour.

\begin{tabular}{|c|c|c|c|c|c|c|}
\hline $\begin{array}{l}\text { Treatment of tumour progression } \\
\text { (no. of patients with tumour } \\
\text { progression/total no. of patients) }\end{array}$ & Surgery & $\begin{array}{l}\text { Surgery } \\
\text { combined } \\
\text { with RT }\end{array}$ & RT & $\begin{array}{c}\text { Cyst } \\
\text { puncture }\end{array}$ & $\begin{array}{l}\text { Cyst puncture } \\
\text { combined } \\
\text { with RT }\end{array}$ & $\begin{array}{l}\text { Clinically insigni- } \\
\text { ficant tumour } \\
\text { progression }^{\mathrm{a}}\end{array}$ \\
\hline All GHRT patients $(9 / 56)$ & 4 & 4 & 1 & - & - & - \\
\hline No initial RT and no residual tumour (4/21) & 3 & 1 & - & - & - & - \\
\hline No initial RT and residual tumour $(4 / 5)$ & - & 3 & 1 & - & - & - \\
\hline Initial RT and no residual tumour (1/19) & 1 & - & - & - & - & - \\
\hline Initial RT and residual tumour $(0 / 11)$ & - & - & - & - & - & - \\
\hline All non-GHRT patients $(30 / 70)$ & 14 & 8 & - & 1 & 2 & 5 \\
\hline No initial RT and no residual tumour $(16 / 35)$ & 10 & 5 & - & - & - & 1 \\
\hline No initial RT and residual tumour $(9 / 12)$ & 2 & 3 & - & - & 2 & 2 \\
\hline Initial RT and no residual tumour (0/2) & - & - & - & - & - & - \\
\hline Initial RT and residual tumour (5/21) & 2 & - & - & 1 & - & 2 \\
\hline
\end{tabular}

$\mathrm{CP}$, craniopharyngioma; GHRT, GH replacement therapy; RT, radiation therapy.

${ }^{a}$ Clinically significant tumour progression was defined as tumour progression resulting in additional tumour treatment.

patients with tumour progression were subsequently treated with surgery in 18 cases, combined surgery and RT in 12 cases, RT alone in one case, combined cyst puncture and RT in two cases, cyst puncture alone in one case and expectation was considered adequate in five cases (Table 3).

The tumour progression outcomes were analysed using Cox regression, which showed that initial RT and the absence of residual tumour after primary treatment were independently associated with a significantly lower frequency of tumour progression whereas age at diagnosis and gender had no significant effect on the frequency of tumour progression. The results of the Cox regressions are shown in Table 4.

All patients were divided into four groups depending on whether they were primarily treated with RT (yes/no) and whether they had a residual tumour after primary treatment (yes/no). The 5-, 10- and 15-year PFSRs are presented in Table 2. In all patients who had received initial RT, the 10-year PFSR was 90\% compared with $58 \%$ of those without RT as part of their primary treatment. The statistical analysis showed a significant difference in PFSR between the patients in the four subgroups (Fig. 1). The best long-term PFSR was seen in patients treated with initial RT without a residual tumour whereas patients not treated with initial RT but who had a residual tumour had the worst outcome.

When the progression rate for the subgroup of patients without initial RT and with no visible residual tumour was used as baseline, the estimated HRs (95\% CI for HR; $P$ value) for tumour progression were (adjusted for gender) $3.0(1.5-6.1 ;<0.005)$ for patients without initial RT and a residual tumour; 0.1 (0.01-0.79; 0.03) for patients with initial RT and no residual tumour; and $0.4(0.16-1.1$; 0.08$)$ for patients with initial RT and a residual tumour (Fig. 1B).

Table 4 Cox regressions analysing possible factors influencing the progression-free survival rates in craniopharyngioma patients.

\begin{tabular}{llcc}
\hline $\begin{array}{l}\text { Cox regression analysis of possible factors } \\
\text { influencing tumour progression }\end{array}$ & HR & $\mathbf{9 5 \%}$ Cl HR & P value \\
\hline All patients $(n=126)$ & & & \\
RT part of initial tumour treatment & 0.13 & $0.05-0.33$ & $<0.001$ \\
Residual tumour after primary treatment & 3.2 & $1.6-6.2$ & $<0.001$ \\
Age at diagnosis & 1.0 & $1.0-1.0$ & 0.40 \\
Gender & 0.55 & $0.28-1.1$ & 0.08 \\
Evaluation of GHRT $_{\text {Treated with GHRT }}$ & 0.57 & $0.26-1.3$ & 0.17 \\
RT part of initial tumour treatment & 0.16 & $0.06-0.40$ & $<0.001$ \\
Residual tumour after primary treatment & 2.6 & $1.3-5.3$ & $<0.01$ \\
Gender & 0.57 & $0.29-1.1$ & 0.10 \\
Evaluation of GHRT by clinically significant & & & \\
tumour progression & & & \\
Treated with GHRT & 0.65 & $0.29-1.5$ & 0.30 \\
RT part of initial tumour treatment & 0.12 & $0.04-0.36$ & $<0.001$ \\
Residual tumour after primary treatment & 2.2 & $1.1-4.7$ & $<0.04$ \\
Gender $^{\mathrm{a}}$ & 0.72 & $0.35-1.4$ & 0.35 \\
\hline
\end{tabular}

GHRT, GH replacement therapy; $R T$, radiation therapy; HR, hazard ratio.

aale coded 1 and female coded 0 .

${ }^{\mathrm{b}}$ Clinically significant tumour progression was defined as tumour progression resulting in additional tumour treatment. 
A The effects of initial RT and residual tumour on progression-free survival

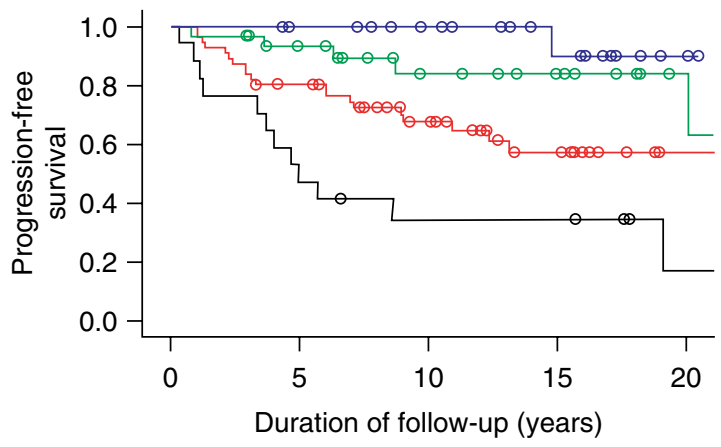

Groups

\begin{tabular}{|lc|}
\hline$\neg$ RT and no residual tumour & RT and no residual \\
tumour censored \\
$\neg$ RT and residual tumour & RT and residual \\
$\neg$ No RT and no residual tumour & tumour censored \\
$\neg$ No RT and residual tumour & No RT and no residual \\
& tumour censored \\
& No RT and residual \\
& tumour censored
\end{tabular}

B

Risk of tumour progression depending on initial RT and residual tumour adjusted for gender

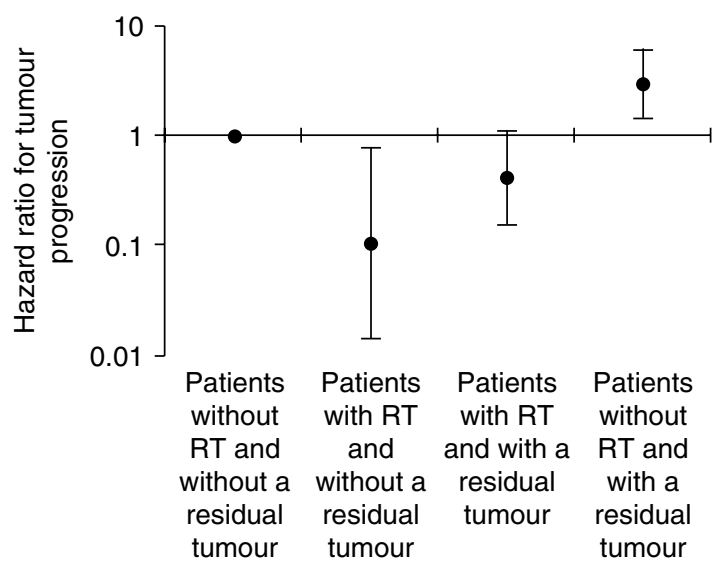

Figure 1 (A) Kaplan-Meier curve showing progression-free survival rate in four different subgroups: (1) patients treated with initial RT who had no residual tumour, (2) patients treated with initial RT who had a residual tumour, (3) patients treated without initial RT who had no residual tumour and (4) patients treated without initial RT who had a residual tumour. The circles indicate censored patients. A significant difference was found between subgroup number 1 vs $3(P<0.01)$, 3 vs $4(P<0.01)$ and 2 vs $4(P<0.001)$. (B) The dots in the table chart show the gender-adjusted $\mathrm{h}$. The HR and the bars show the $95 \% \mathrm{Cl}$ for each group. Patients without initial RT and without a visible residual tumour are set as baseline. The $\mathrm{HR}(95 \% \mathrm{Cl}$ for $\mathrm{HR}$; $P$ value) for tumour progression was $0.1(0.01-0.79 ; 0.03)$ for patients with initial RT and without a residual tumour; 0.4 (0.16$1.1 ; 0.08)$ for patients with initial RT and with a residual tumour; and $3.0(1.5-6.1 ;<0.005)$ for patients without initial RT and with a residual tumour (RT, radiation therapy).

\section{Tumour progression in patients treated with GHRT}

Of the 56 patients treated with GHRT, nine (16\%) developed tumour progression. In patients treated with GHRT, the estimated 10-year PFSR was $88 \%$ (Table 2). All tumour recurrences or enlargements were clinically significant. In the nine cases, where tumour progression occurred, eight patients had initially undergone surgery alone whereas one patient had undergone surgery and RT (Table 5).

The influence of initial RT on tumour PFSR is presented in Table 5. Tumour treatments targeting tumour progression divided depending on initial therapy are presented in Table 3.

In all patients with GHRT, the mean of the last serum IGF 1 concentration was $222 \pm 107 \mathrm{mg} / \mathrm{l}$. There was no significant difference in the serum IGF1 level $(P=0.35)$ or the SDS $(P=0.15)$ between patients with tumour progression $(266 \pm 138 \mathrm{mg} / \mathrm{l}$; IGF1 SDS $1.23 \pm 2.3)$ and patients without tumour progression $(214 \pm 100 \mathrm{mg} / \mathrm{l}$; IGF1 SDS $0.10 \pm 2.1$ ).

\section{Tumour progression in patients not treated with GHRT}

Of the 70 patients not receiving GHRT, $30(43 \%)$ developed tumour progression. The 10-year PFSR was $57 \%$ for patients not treated with GHRT (Table 2). Five out of 30 patients developed clinically insignificant tumour progression. In the cases where tumour progression occurred, the initial tumour treatment was surgery alone in 24 patients, combined surgery and RT in three patients, cyst puncture in one patient and combined cyst puncture and RT in two patients (Table 5).

The effect of initial RT on tumour PFSR for patients not treated with GHRT is shown in Table 5. Tumour treatments targeting tumour progression divided depending on initial therapy are presented in Table 3.

\section{Comparison of tumour progression in patients with and without GHRT}

The 10-year PFSRs in patients treated with and without GHRT were 88 and $57 \%$ respectively. A Cox regression analysis showed that initial RT and absence of residual tumour after primary treatment were significantly associated with higher PFSR whereas treatment with GHRT and gender did not affect the PFSR (Table 4). Adjusted for these uneven distributed factors, the 10-year PFSRs were $85 \%$ in patients treated with GHRT and $65 \%$ in patients not treated with GHRT (Fig. 2).

When considering only patients with a clinically significant tumour progression (i.e. needing further tumour treatment), the 10 -year PFSRs were $88 \%$ for the patients treated with GHRT and $63 \%$ for patients not treated with GHRT. Cox regression analysis showed that initial RT and absence of residual tumour after primary 
Table 5 Tumour progression rates in patients with and without GHRT and a comparison of subgroups with regard to initial radiation therapy.

\begin{tabular}{lccc}
\hline & $\begin{array}{c}\text { Tumour } \\
\text { progression }(n(\%))\end{array}$ & $\begin{array}{c}\text { No tumour } \\
\text { progression }(n(\%))\end{array}$ & $\begin{array}{c}\text { No tumour progression and } \\
\text { clinically insignificant } \\
\text { tumour progression }\end{array}$ \\
& $(n(\%))$
\end{tabular}

GHRT, GH replacement therapy; RT, radiation therapy.

${ }^{\mathrm{a} C}$ Clinically insignificant tumour progression was defined as tumour progression not resulting in additional tumour treatment.

treatment were associated with significantly higher clinical PFSR whereas GHRT and gender did not affect the clinical PFSR (Table 4). Adjusted for these uneven distributed factors, the 10-year clinical PFSRs were 85\% in GHRT patients and 69\% in non-GHRT patients.

No associations between tumour progression or clinically significant tumour progression and GHRT were found.

\section{Discussion}

This study on $126 \mathrm{CP}$ patients with and without GHRT, who had a mean follow-up of over 13 years, provides new long-term follow-up data and allows for an evaluation of GHRT effect on tumour progression rate. In the current study, the overall 10- and 15-year PFSRs were 72 and $67 \%$ respectively. The strongest predictors of tumour PFS were initial RT and tumour status after the primary tumour treatment, whereas long-term GHRT had no significant impact on tumour progression.

The tumour progression rate in patients with $\mathrm{CPs}$ is high but differs widely in earlier studies mainly depending on the extent of surgical removal and if initial RT was used. Reports with follow-ups of 10 years or more in $\mathrm{CP}$ patients are scarce, but earlier papers have reported a 10-year PFSR of $41 \%$ in CP patients not treated with initial RT who had a residual tumour or $42-81 \%$ where there was no residual tumour $(23,24$, $25,26)$. In the current study, the 10-year PFSRs in CP patients not primarily treated with RT and with or without a residual tumour after the initial treatment were $32 \%$ and $66 \%$ respectively. The addition of RT to the primary treatment has been reported to increase the 10-year PFSRs in CP patients with and without a residual tumour after the initial tumour treatment to $84-90 \%$ and almost $100 \%$ respectively $(23,24,27)$. The corresponding results in our study were 82 and $100 \%$.

The two most important predictive factors, according to this study, for tumour PFSR were initial RT and the absence of a residual tumour after primary tumour treatment. Although the tumour progression rate is considerably lower in patients in whom total tumour removal has been ensured, there is a risk that an aggressive surgical approach would cause extensive hypothalamic injury with a poorer metabolic and neuropsychological outcome (28). Therefore, in many patients, the goal is not to achieve a radical tumour removal but to perform tumour debulking and, if needed, combine with adjuvant RT in order to minimise tumour progression.

Initial treatment with RT was the single most important factor for preventing tumour progression. However, RT is also associated with an increased risk of developing additional pituitary hormone deficiencies $(29,30)$, an increased risk of optic neuropathy $(29,30)$, secondary brain tumours (31) and cerebrovascular accidents $(32,33)$. In many centres, the practice of RT has therefore been used more restrictively during later years, although its use is still frequent in CPs due to their high risk of tumour progression. This study does not add any information on the risk-benefit of RT except for the aspects related to long-term tumour progression rates.

No correlation between age at diagnosis of $\mathrm{CP}$ and tumour progression was found in this study, which is in agreement with earlier studies $(23,27,34)$. Thus, our results are in line with the previous reports and add

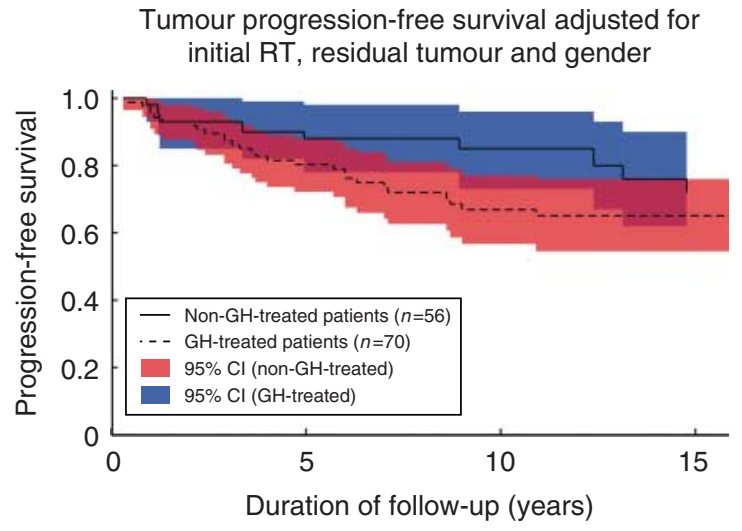

Figure 2 Cox regression of progression-free survival rates adjusted for initial RT, residual tumour after primary treatment and gender in patients treated with and without GHRT. No association between GHRT and tumour progression was found (HR 0.57; Cl for GHRT $0.26-1.3 ; P$ value $=0.17)$. The $95 \% \mathrm{Cl}$ for each group are indicated by the red and blue colours (GHRT, GH replacement therapy; RT, radiation therapy). 
further to the limited available data on the long-term follow-up of tumour progression in CP patients.

Our study does not lend support to the concern that long-term GHRT increases the risk of tumour recurrence or tumour enlargement in $\mathrm{CP}$ patients. There are only a few previous studies comparing the tumour progression rate in CP patients with and without GHRT. Karavitaki et al. (35) reported no influence of 6 years of GHRT on tumour progression rate in $32 \mathrm{GH}$-treated patients. The study had, however, a large difference in the frequency of initial RT between the GH-treated and non-GH-treated patients. In a recent study from Müller et al. (36), there was no difference in tumour progression between $54 \mathrm{CP}$ patients treated with GHRT and $60 \mathrm{CP}$ patients without GHRT after a mean follow-up of 2.8 years. In the current study, after adjustment for initial RT, residual tumour after primary treatment and gender, the 10-year PFSRs were $85 \%$ for the GHRT-treated patients and 65\% for patients not treated with GHRT. Furthermore, circulating levels of IGF1 in the GHRT group, which are closely correlated with the biological effect of $\mathrm{GH}$, were not different in $\mathrm{CP}$ patients with and without tumour progression. Our results, therefore, support the previous reports that physiological doses of $\mathrm{GH}$ as replacement therapy does not influence the rate of tumour progression in patients with CP.

Selection bias is a possible limitation of this trial as all GHRT patients were treated and followed at one university clinic, whereas the patients without GHRT were treated at another centre. The distributions in age at diagnosis and in the year of diagnosis were similar for both centres. A potential selection bias would occur if CP patients with GHD from the Gothenburg clinic were excluded from GHRT because of a residual tumour with a high risk of tumour progression. This is unlikely as we only found two patients with GHD who had not been included in the original GHD cohort from the clinic in Gothenburg, due to lack of medical records and due to their being lost to follow-up. Childhood-onset and adultonset CPs have not been analysed separately, as age at diagnosis did not affect the rate of tumour progression in this study or in earlier studies $(23,27,34)$ (see Table 4).

The management of patients with $\mathrm{CP}$ is a clinical challenge both in terms of the best choice of primary tumour treatment and the long-term management of the endocrine and metabolic consequences of the tumour itself and its treatment. In summary, our study with 13 years of follow-up highlights the effect of initial RT and the absence of a residual tumour on tumour progression rates in $\mathrm{CP}$ patients. In addition, long-term GHRT and serum IGF1 concentrations did not influence the risk of tumour recurrence or tumour enlargement. Based on our results from this large study with long-term follow-up, we conclude that GHRT does not increase the risk of tumour recurrence or tumour enlargement in CP patients.

\section{Declaration of interest}

Authors D S Olsson, M Buchfelder, K Wiendieck, N Kremenevskaja, B-Å Bengtsson, K-E Jakobsson, M Jarfelt and A G Nilsson have nothing to declare. G Johannsson has received grant support from NovoNordisk and honorarium from NovoNordisk, Pfizer, Eli Lilly and Merck Serono.

\section{Funding}

This study received unrestricted financial support from the Swedish government under the LUA/ALF agreement and Novo Nordisk.

\section{Acknowledgements}

We would like to express our gratitude to the staff at the Centre for Endocrinology and Metabolism at the Department of Endocrinology at Sahlgrenska University Hospital and all the colleagues who have been very helpful at the Department of Neurosurgery, University of Erlangen-Nuremberg. We would also like to thank Martin Olsson for his help with image processing. The authors acknowledge statistical support from Kirsten Mehlig (Department of Public Health and Community Medicine at Gothenburg University).

\section{References}

1 Karavitaki N, Cudlip S, Adams CB \& Wass JA. Craniopharyngiomas. Endocrine Reviews 200627 371-397. (doi:10.1210/er. 2006-0002)

2 Van Effenterre R \& Boch AL. Craniopharyngioma in adults and children: a study of 122 surgical cases. Journal of Neurosurgery 200297 3-11. (doi:10.3171/jns.2002.97.1.0003)

3 Chakrabarti I, Amar AP, Couldwell W \& Weiss MH. Long-term neurological, visual, and endocrine outcomes following transnasal resection of craniopharyngioma. Journal of Neurosurgery 2005 102 650-657. (doi:10.3171/jns.2005.102.4.0650)

4 Bulow B, Attewell R, Hagmar L, Malmstrom P, Nordstrom CH \& Erfurth EM. Postoperative prognosis in craniopharyngioma with respect to cardiovascular mortality, survival, and tumor recurrence. Journal of Clinical Endocrinology and Metabolism $1998 \mathbf{8 3}$ 3897-3904. (doi:10.1210/jc.83.11.3897)

5 Tomlinson JW, Holden N, Hills RK, Wheatley K, Clayton RN, Bates AS, Sheppard MC \& Stewart PM. Association between premature mortality and hypopituitarism. West Midlands Prospective Hypopituitary Study Group. Lancet 2001357 425-431. (doi:10.1016/S0140-6736(00)04006-X)

6 Pereira AM, Schmid EM, Schutte PJ, Voormolen JH, Biermasz NR, van Thiel SW, Corssmit EP, Smit JW, Roelfsema F \& Romijn JA. High prevalence of long-term cardiovascular, neurological and psychosocial morbidity after treatment for craniopharyngioma. Clinical Endocrinology 200562 197-204. (doi:10.1111/j.1365-2265. 2004.02196.x)

7 Rosen T, Wiren L, Wilhelmsen L, Wiklund I \& Bengtsson BA. Decreased psychological well-being in adult patients with growth hormone deficiency. Clinical Endocrinology 199440 111-116. (doi:10.1111/j.1365-2265.1994.tb02452.x)

8 Burman P, Broman JE, Hetta J, Wiklund I, Erfurth EM, Hagg E \& Karlsson FA. Quality of life in adults with growth hormone (GH) deficiency: response to treatment with recombinant human $\mathrm{GH}$ in a placebo-controlled 21-month trial. Journal of Clinical Endocrinology and Metabolism 1995 80 3585-3590. (doi:10.1210/jc.80.12.3585)

9 Holmes SJ, Economou G, Whitehouse RW, Adams JE \& Shalet SM. Reduced bone mineral density in patients with adult onset growth hormone deficiency. Journal of Clinical Endocrinology and Metabolism 199478 669-674. (doi:10.1210/jc.78.3.669)

10 Rosen T \& Bengtsson BA. Premature mortality due to cardiovascular disease in hypopituitarism. Lancet 1990336 285-288. (doi:10.1016/0140-6736(90)91812-O) 
11 Gotherstrom G, Svensson J, Koranyi J, Alpsten M, Bosaeus I, Bengtsson B \& Johannsson G. A prospective study of 5 years of GH replacement therapy in $\mathrm{GH}$-deficient adults: sustained effects on body composition, bone mass, and metabolic indices. Journal of Clinical Endocrinology and Metabolism 200186 4657-4665. (doi:10.1210/jc.86.10.4657)

12 Gotherstrom G, Bengtsson BA, Bosaeus I, Johannsson G \& Svensson J. A 10-year, prospective study of the metabolic effects of growth hormone replacement in adults. Journal of Clinical Endocrinology and Metabolism 200792 1442-1445. (doi:10.1210/jc.2006-1487)

13 Carroll PV, Christ ER, Bengtsson BA, Carlsson L, Christiansen JS, Clemmons D, Hintz R, Ho K, Laron Z, Sizonenko P, Sonksen PH, Tanaka T \& Thorne M. Growth hormone deficiency in adulthood and the effects of growth hormone replacement: a review. Growth Hormone Research Society Scientific Committee. Journal of Clinical Endocrinology and Metabolism 199883 382-395. (doi:10.1210/ jc.83.2.382)

14 Verhelst J, Kendall-Taylor P, Erfurth EM, Price DA, Geffner M, Koltowska-Haggstrom M, Jonsson PJ, Wilton P \& Abs R. Baseline characteristics and response to 2 years of growth hormone (GH) replacement of hypopituitary patients with GH deficiency due to adult-onset craniopharyngioma in comparison with patients with nonfunctioning pituitary adenoma: data from KIMS (Pfizer International Metabolic Database). Journal of Clinical Endocrinology and Metabolism 200590 4636-4643. (doi:10.1210/jc.20050185)

15 Samani AA, Yakar S, LeRoith D \& Brodt P. The role of the IGF system in cancer growth and metastasis: overview and recent insights. Endocrine Reviews 200728 20-47. (doi:10.1210/er. 2006-0001)

16 Pollak MN, Schernhammer ES \& Hankinson SE. Insulin-like growth factors and neoplasia. Nature Reviews. Cancer 20044 505-518. (doi:10.1038/nrc1387)

17 Olsson DS, Buchfelder M, Schlaffer S, Bengtsson BA, Jakobsson KE, Johannsson G \& Nilsson AG. Comparing progression of nonfunctioning pituitary adenomas in hypopituitarism patients with and without long-term GH replacement therapy. European Journal of Endocrinology 2009161 663-669. (doi:10.1530/EJE09-0572)

18 Buchfelder M, Kann PH, Wuster C, Tuschy U, Saller B, Brabant G, Kleindienst A \& Nomikos P. Influence of GH substitution therapy in deficient adults on the recurrence rate of hormonally inactive pituitary adenomas: a case control study. European Journal of Endocrinology 2007157 149-156. (doi:10.1530/EJE-07-0164)

19 Johannsson G, Rosen T \& Bengtsson BA. Individualized dose titration of growth hormone $(\mathrm{GH})$ during $\mathrm{GH}$ replacement in hypopituitary adults. Clinical Endocrinology 199747 571-581. (doi:10.1046/j.1365-2265.1997.3271123.x)

20 Drake WM, Coyte D, Camacho-Hubner C, Jivanji NM, Kaltsas G, Wood DF, Trainer PJ, Grossman AB, Besser GM \& Monson JP. Optimizing growth hormone replacement therapy by dose titration in hypopituitary adults. Journal of Clinical Endocrinology and Metabolism 199883 3913-3919. (doi:10.1210/jc.83.11. 3913)

21 Svensson J, Johannsson G \& Bengtsson BA. Insulin-like growth factor-I in growth hormone-deficient adults: relationship to population-based normal values, body composition and insulin tolerance test. Clinical Endocrinology $1997 \quad 46 \quad 579-586$. (doi:10.1046/j.1365-2265.1997.1851001.x)

22 Zhang X, Loberiza FR, Klein JP \& Zhang MJ. A SAS macro for estimation of direct adjusted surival curves based on a stratified Cox regression model. Computer Methods and Programs in Biomedicine 200788 95-101. (doi:10.1016/j.cmpb.2007.07.010)

23 Duff J. Long-term outcomes for surgically resected craniopharyngiomas. Neurosurgery 2000 46 291-302 discussion 302-305. (doi:10.1097/00006123-200002000-00007)
24 Stripp DCH, Janss AJ, Belasco JB, Tochner ZA, Goldwein JW, Moshang T, Rorke LB, Phillips PC, Sutton LN \& Shu H-KG. Surgery with or without radiation therapy in the management of craniopharyngiomas in children and young adults. International Journal of Radiation Oncology, Biology, Physics 200458 714-720. (doi:10.1016/S0360-3016(03)01570-0)

25 Fahlbusch R, Honegger J, Paulus W, Huk W \& Buchfelder M. Surgical treatment of craniopharyngiomas: experience with 168 patients. Journal of Neurosurgery 199990 237-250. (doi:10. 3171/jns.1999.90.2.0237)

26 De Vile CJ, Grant DB, Kendall BE, Neville BG, Stanhope R, Watkins KE \& Hayward RD. Management of childhood craniopharyngioma: can the morbidity of radical surgery be predicted? Journal of Neurosurgery 199685 73-81. (doi:10.3171/jns.1996. 85.1.0073)

27 Rajan B, Ashley S, Gorman C, Jose CC, Horwich A, Bloom HJ, Marsh H \& Brada M. Craniopharyngioma - a long-term results following limited surgery and radiotherapy. Radiotherapy and Oncology 199326 1-10. (doi:10.1016/0167-8140(93)90019-5)

28 Honegger J \& Tatagiba M. Craniopharyngioma surgery. Pituitary 200811 361-373. (doi:10.1007/s11102-008-0137-z)

29 Minniti G, Jaffrain-Rea ML, Osti M, Cantore G \& Enrici RM. Radiotherapy for nonfunctioning pituitary adenomas: from conventional to modern stereotactic radiation techniques. Neurosurgical Review 200730 167-175 discussion 175-176. (doi:10.1007/s10143-007-0072-x)

30 Boelaert K \& Gittoes NJ. Radiotherapy for non-functioning pituitary adenomas. European Journal of Endocrinology $2001 \mathbf{1 4 4}$ 569-575. (doi:10.1530/eje.0.1440569)

31 Minniti G, Traish D, Ashley S, Gonsalves A \& Brada M. Risk of second brain tumor after conservative surgery and radiotherapy for pituitary adenoma: update after an additional 10 years. Journal of Clinical Endocrinology and Metabolism 200590 800-804. (doi:10.1210/jc.2004-1152)

32 Erfurth EM, Bulow B, Svahn-Tapper G, Norrving B, Odh K, Mikoczy Z, Bjork J \& Hagmar L. Risk factors for cerebrovascular deaths in patients operated and irradiated for pituitary tumors. Journal of Clinical Endocrinology and Metabolism $2002 \quad 87$ 4892-4899. (doi:10.1210/jc.2002-020526)

33 Brada M, Ashley S, Ford D, Traish D, Burchell L \& Rajan B. Cerebrovascular mortality in patients with pituitary adenoma. Clinical Endocrinology 200257 713-717. (doi:10.1046/j.13652265.2002.01570.x)

34 Karavitaki N, Brufani C, Warner JT, Adams CB, Richards P, Ansorge O, Shine B, Turner HE \& Wass JA. Craniopharyngiomas in children and adults: systematic analysis of 121 cases with long-term follow-up. Clinical Endocrinology 200562 397-409. (doi:10.1111/j.1365-2265.2005.02231.x)

35 Karavitaki N, Warner JT, Marland A, Shine B, Ryan F, Arnold J. Turner HE \& Wass JA. GH replacement does not increase the risk of recurrence in patients with craniopharyngioma. Clinical Endocrinology $2006 \mathbf{6 4}$ 556-560. (doi:10.1111/j.1365-2265.2006. 02508.x)

36 Muller HL, Gebhardt U, Schroder S, Pohl F, Kortmann RD, Faldum A, Zwiener I, Warmuth-Metz M, Pietsch T, Calaminus G, Kolb R, Wiegand C \& Sorensen N. Analyses of treatment variables for patients with childhood craniopharyngioma - results of the multicenter prospective trial KRANIOPHARYNGEOM 2000 after three years of follow-up. Hormone Research in Pediatrics 201073 175-180. (doi:10.1159/000284358)

Received 28 January 2012

Revised version received 14 March 2012

Accepted 28 March 2012 